\title{
A BOVINOCULTURA LEITEIRA NA AGRICULTURA FAMILIAR DO MUNICÍPIO DE BARREIRA, CE
}

Francisco de Assis Pinheiro da Silva Júnior ${ }^{1}$, Maria Gorete Flores Salles ${ }^{2}$, Ciro de Miranda Pinto ${ }^{3}$, Olienaide Ribeiro de Oliveira Pinto ${ }^{4}$, Inti Campos Salles Rodrigues ${ }^{5}$

${ }^{1}$ Bacharel em Agronomia da Universidade da Integração Internacional da Lusofonia Afro-Brasileira (UNILAB), Redenção-CE, Brasil.

2 Professora Doutora do curso de Agronomia da UNILAB, Redenção-CE, Brasil.

E-mail: gorete@unilab.edu.br

${ }^{3}$ Professor Doutor do curso de Agronomia da UNILAB, Redenção-CE, Brasil.

${ }^{4}$ Professora no Mestrado Acadêmico em Sociobiodiversidade e Tecnologias Sustentáveis da UNILAB, Redenção-CE, Brasil.

${ }^{5}$ Mestre em Ciências Veterinárias/ Universidade Estadual do Ceará (UECE), Fortaleza-CE, Brasil.

Recebido em: 22/09/2018 - Aprovado em: 23/11/2018 - Publicado em: 03/12/2018 DOI: 10.18677/EnciBio_2018B1

\begin{abstract}
O trabalho ocorreu durante o verão de 2017, no município de Barreira, região do Maciço de Baturité, no estado do Ceará, com o objetivo de visualizar o perfil dos produtores da agricultura familiar da bovinocultura leiteira. Essa região do Ceará apresenta grande importância socioeconômica e cultural, porém, o setor bovino leiteiro apresenta fragilidades e necessita de ações urgentes que proporcionem o desenvolvimento da cadeia produtiva, tornando-a mais organizada, estruturada, sustentável e competitiva. A região semiárida apresenta grandes limitações com relação às atividades agropecuárias, por irregularidades nas precipitações pluviais associadas às temperaturas elevadas durante o dia e às características físicas dos solos, de forma geral, rasos e pedregosos. O trabalho relata o perfil da atividade bovino leiteira e mostra que mesmo com este cenário adverso, tem um importante papel na sobrevivência das propriedades agrícolas familiares, tanto no autoconsumo como na geração de renda, quanto permite a diversificação e a integração agricultura-pecuária.
\end{abstract}

RESUMO

PALAVRAS-CHAVE: leite bovino, manejo, semiárido cearense

\section{PROFILE OF DAIRY BOVINECULTURE IN THE FAMILY FARMING OF THE MUNICIPALITY OF BARREIRA, CE}

\begin{abstract}
The work was carried out during the summer of 2017, in the municipality of Barreira, in the region of the Baturité Massif, in the state of Ceará, with the objective of visualizing the profile of the producers of the family agriculture of dairy cattle. This region of Ceará has great socioeconomic and cultural importance, however, the dairy cattle sector presents weaknesses and needs urgent actions that provide the
\end{abstract}


development of the productive chain, making it more organized, structured, sustainable and competitive. The semiarid region presents great limitations with regard to agricultural activities, due to irregularities in rainfall associated with high temperatures during the day and the physical characteristics of the soils, generally shallow and stony. The paper reports the profile of dairy cattle activity and shows that even with this adverse scenario, it plays an important role in the survival of family farms, both in self-consumption and income generation, as well as in agriculturelivestock diversification and integration.

KEYWORDS: semiarid cearense, bovine milk, management.

\section{INTRODUÇÃO}

A Organização das Nações Unidas para Agricultura e Alimentação (FAO, 2018) divulgou que a produção mundial de leite deverá crescer em torno de $2 \%$, alcançando 805 milhões de toneladas. No Brasil, a pecuária leiteira bovina tem grande relevância, destacando-se por gerar renda e emprego no setor rural. Ademais, a região Nordeste vem ganhando força de produção na última década, sendo a segunda região que mais cresceu em participação neste período, em torno de $69 \%$, sendo responsável por $12 \%$ de todo o leite produzido no país (IBGE, 2017).

O Ceará ocupa $012^{\circ}$ lugar no ranking dos estados brasileiros produtores de leite bovino, onde nos últimos quinze anos, a produção leiteira cresceu, devido ao aperfeiçoamento da tecnologia adotada na produção. Mesmo com esse bom desempenho sabe-se que essa tecnologia não vem sendo absorvida pelos pequenos produtores rurais (IPECE, 2018).

A região semiárida caracteriza-se pela prática de uma pecuária extensiva paralela a uma exploração agrícola de sequeiro (COUTINHO et al., 2013). No entanto, para o semiárido do Nordeste brasileiro, a atividade pecuária é de extrema importância, sobretudo a criação de ruminantes, que tem se constituído, ao longo tempo, em função das condições edafoclimáticas desfavoráveis, na atividade básica das populações rurais (NÓBREGA et al., 2011).

Assim, a região semiárida apresenta grandes limitações com relação às atividades agropecuárias. No entanto, mesmo com este cenário adverso, no estado do Ceará, a atividade leiteira tem um importante papel na sobrevivência das propriedades agrícolas familiares, tanto no autoconsumo como na geração de renda, o que permite a diversificação da propriedade e a integração agricultura-pecuária.

A irregularidade das precipitações associada às temperaturas elevadas durante o dia e às características físicas dos solos, de forma geral, rasos e pedregosos, é o fator limitante da produção agropecuária nordestina, que influencia diretamente a fisiologia dos animais e a produção vegetal destinada à alimentação do rebanho (XIMENES, 2014). Entretanto, a bovinocultura leiteira vem evoluindo em produtividade, ao longo dos últimos anos, no Ceará. Essa evolução é um reflexo do profissionalismo com que a atividade está sendo conduzida, destacando-se os investimentos realizados pelos produtores nas áreas de infraestrutura alimentar, manejo sanitário e reprodutivo, bem como no uso de raças adaptadas ao clima quente.

A maior parte dos criatórios de bovinos leiteiros no semiárido é composta por estabelecimentos familiares, com baixo nível de inovação tecnológica e sazonalidade da produção, em função do clima e os seus períodos seco e chuvoso. Os regimes de criação predominantes são o extensivo e o semi intensivo, nos quais os animais utilizam a vegetação nativa do bioma caatinga para sua mantença e produção (GALVÃO JÚNIOR et al., 2015). 
O desenvolvimento de pesquisas voltadas ao conhecimento da estrutura e da distribuição espacial da pecuária leiteira é de grande relevância para a definição de políticas de infraestrutura, transporte, logística, análise de viabilidade de projetos de desenvolvimento regional e de programas de colonização e assentamento. É também importante para o estabelecimento de estratégias em vigilância sanitária, rastreabilidade, avaliação de risco geográfico de doenças e estudos de dinâmica do setor agropecuário (ZOCCAL et al., 2006).

O município de Barreira, em pleno sertão cearense, no Maciço de Baturité, está sendo beneficiado e tem consolidado o projeto Balde Cheio, desenvolvido pela Embrapa, que capacita e introduz aos produtores de leite bovino, novas tecnologias que aumentem a produtividade, fato que tem assegurado o crescimento da produção de leite mesmo numa época de escassez de chuvas. Neste contexto, o acompanhamento, a coleta e a organização dos dados produtivos das propriedades leiteiras atendidas pelo projeto são o objetivo deste estudo, com o intuito de divulgar e motivar a todos os pequenos produtores da região para que transformem seus manejos, em busca de alavancar a produtividade, bem como, conhecer o perfil dessas propriedades produtoras de leite bovino no município de Barreira

\section{Localização e caracterização da área de estudo \\ MATERIAL E MÉTODOS}

O estudo foi realizado no município de Barreira, estado do Ceará, situado à latitude 417'13"Sul, longitude 3838'34"Oeste e altitude de 318m. Com relação aos aspectos climáticos, o clima da região é tropical quente semiárido brando com temperatura média anual de $28^{\circ} \mathrm{C}$, pluviosidade anual de $1061,9 \mathrm{~mm}$ com o período chuvoso entre fevereiro a abril. Nos componentes ambientais o relevo é formado por maciço residual e depressão sertaneja, com solos aluvias, areias quartzosas distróficas, planossolo solódico e podzólico vermelho-amarelo, contendo vegetação de caatinga arbustiva densa, floresta subcaducifolia tropical pluvial. O município de Barreira possui $245,946 \mathrm{Km}^{2}$ de área geográfica, distante $63 \mathrm{Km}$ da capital Fortaleza, com uma população de 20.978 habitantes, sendo que 41,52\% reside em área urbana e 58,48\% na zona rural (IPECE, 2017).

\section{Período de estudo}

O trabalho foi realizado durante três meses (setembro, outubro e novembro) de 2017 em dez propriedades de criação de bovinos leiteiros.

\section{Caracterização do estudo}

Inicialmente, os objetivos do trabalho foram explicados em cada propriedade visitada, sendo solicitada a colaboração voluntária dos agricultores familiares e, espontaneamente, as pessoas a serem entrevistadas assinaram o termo de consentimento livre e esclarecido (TCLE). Uma vez aceita a participação, deu-se início à entrevista.

É possível, por meio de entrevista estruturada, que é caracterizada por perguntas fechadas e análise quantitativa por meio dos conhecimentos da estatística (MANZINI, 2012), conhecer diversos aspectos relacionados aos sistemas de produção de leite.

\section{Coleta dos dados}

Foi utilizada uma abordagem de pesquisa de campo através de um questionário de base quanti-qualitativa produzido numa sequência lógica tematizada. 
Através do diálogo com o produtor leiteiro foram obtidas as respostas do questionário elaborado. No momento da entrevista foram feitas fotografias, com a permissão dos produtores, desde fotos nas áreas de instalações até dos animais. Em cada propriedade foi gerada uma coordenada geográfica através de GPS (GARMIN).

Durante a coleta de dados foram abordadas questões para o conhecimento dos seguintes manejos da propriedade com relação as crias, nutricional, sanitário, reprodutivo, ordenha, das raças utilizadas e sobre o escore da condição corporal.

\section{Análise estatística}

A pesquisa foi exploratória fundamentada em análise qualitativa e interpretativa, baseada na realidade observada. Os dados coletados foram organizados e analisados por meio de métodos da estatística descritiva, com sínteses apresentadas na forma de gráficos e tabelas pelo Word e Excel.

\section{Área de estudo}

\section{RESULTADOS E DISCUSSÃO}

A figura 1 mostra a área do município de Barreira-CE. Através do GPS as áreas visitadas para a execução do questionário foram demarcadas e são mostradas nas figuras 1 e 2 .

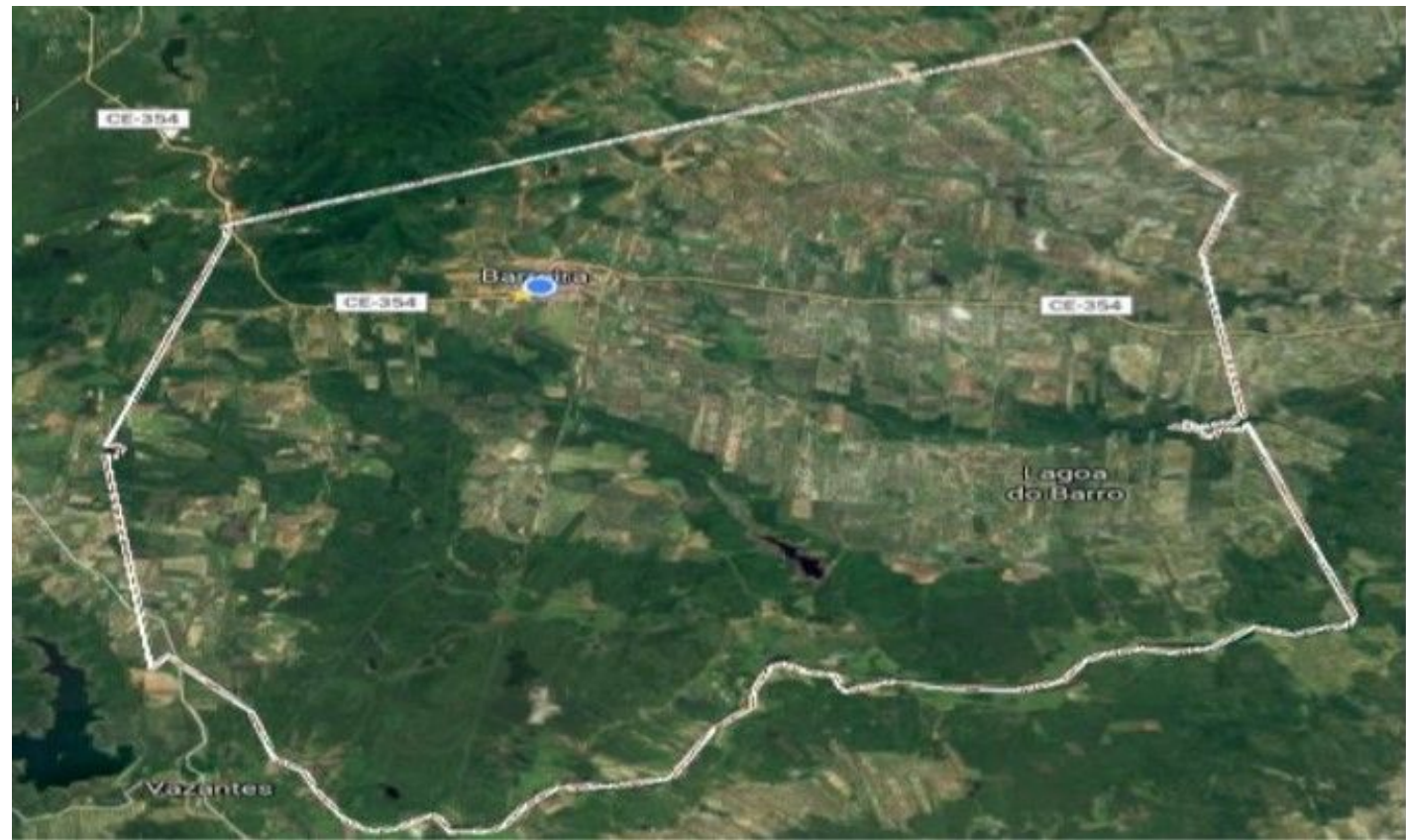

FIGURA 1- Área geográfica do município de Barreira - Ceará.

Os 10 locais de criação de bovinos são mostrados na figura 2, pelos pontos georreferenciados (293 a 303), situados nas localidades de Lagoa Grande (293 e 297), Bom Sucesso (295 e 300), Areré (296), Boqueirão (298 e 299), Olaria (301 e 302) e no Centro (303) do município de Barreira. 


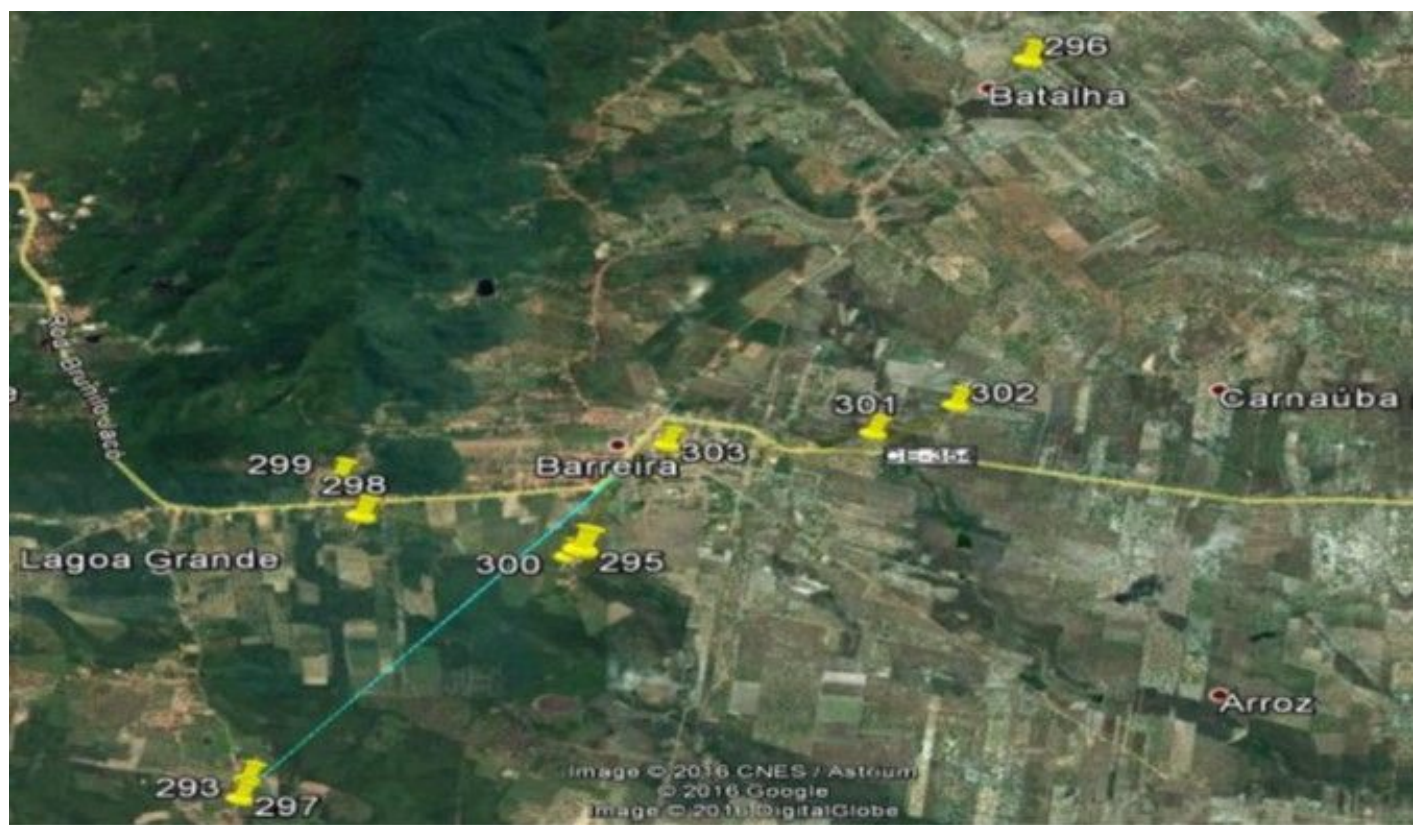

FIGURA 2- Pontos de georreferenciamento das propriedades que criam bovinos

É possível, por meio de entrevista, conhecer diversos aspectos relacionados aos sistemas de produção de leite. Os tipos clássicos de entrevista são: não estruturada, semiestruturada e estruturada. Enquanto a entrevista não estruturada não possui roteiro previamente estabelecido, a entrevista semiestruturada possui roteiro com perguntas abertas e a entrevista estruturada é caracterizada por perguntas fechadas e análise quantitativa por meio dos conhecimentos da estatística (MANZINI, 2012). Assim, pode-se obter a caracterização dos produtores, quanto aos aspectos abaixo:

\section{- Tamanho do rebanho}

Apresentado na Tabela 1, onde foram mostrados o número de animas em cada uma das 10 propriedades entrevistadas. O presente trabalho pôde proporcionar uma análise numérica na contabilização de cabeças das propriedades analisadas.

TABELA 1- Tamanho do rebanho bovino em 10 propriedades no município de Barreira

\begin{tabular}{lc}
\hline Quantidade de cabeças & Propriedades (\%) \\
\hline Até 10 cabeças & $0 \%$ \\
De 10 a 20 cabeças & $30 \%$ \\
De 20 a 30 cabeças & $0 \%$ \\
De 30 a 40 cabeças & $20 \%$ \\
De 40 a 50 cabeças & $30 \%$ \\
Mais de 50 cabeças & $20 \%$ \\
\hline
\end{tabular}

\section{- Padrão racial do rebanho}

O estudo encontrou animais mestiços das seguintes raças bovinas de leite sendo criadas pelos produtores do município de Barreira: Holandês, Gir, Guzerá, Pardo Suíço e Jersey (Figura 3). Também foram encontrados animais mestiços de raças leiteiras com o Nelore, visando melhorar geneticamente o volume de carne desses animais, especialmente quando as crias são do sexo masculino, ou mesmo no momento do abate quando do descarte de fêmeas. 
Vale salientar que $56 \%$ dos animais tem mestiçagem com grupo genético de Bos indicus os quais são mais resistentes ao clima semiárido da região.

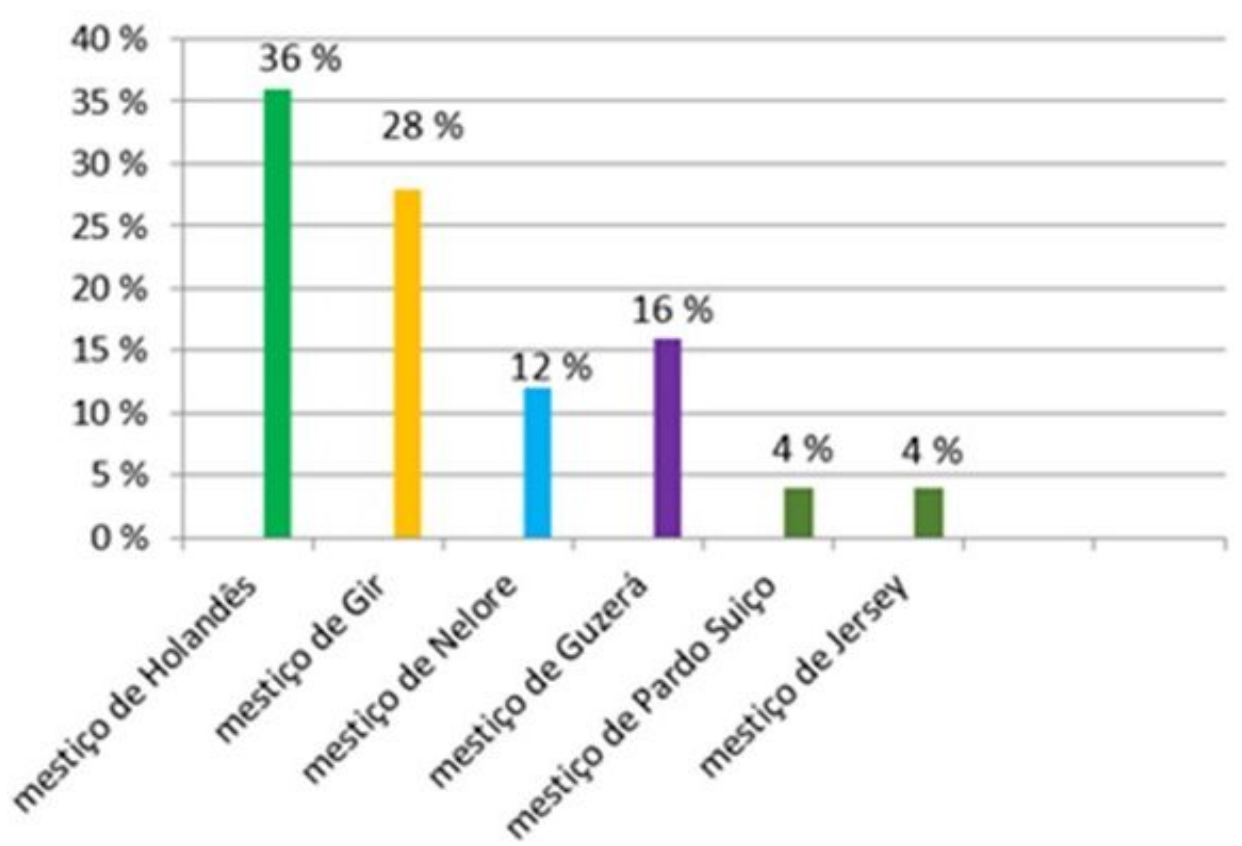

FIGURA 3- Porcentagens da mestiçagem do rebanho leiteiro de Barreira-CE.

\section{- Controle reprodutivo do rebanho}

Quanto ao critério adotado para definir o momento da primeira cobertura, em $100 \%$ das propriedades não existe, pois, o reprodutor é sempre presente no rebanho. Não havendo separação de categorias. Também não existe critério, como peso e idade, para definir a cobertura das matrizes e novilhas. A cobertura acontecerá no aparecimento do cio, que ocorre primeiramente nas fêmeas mestiças de Holandês (70\%), seguido de vacas Nelore (20\%) e mestiças de Gir (10\%), conforme a figura 4.

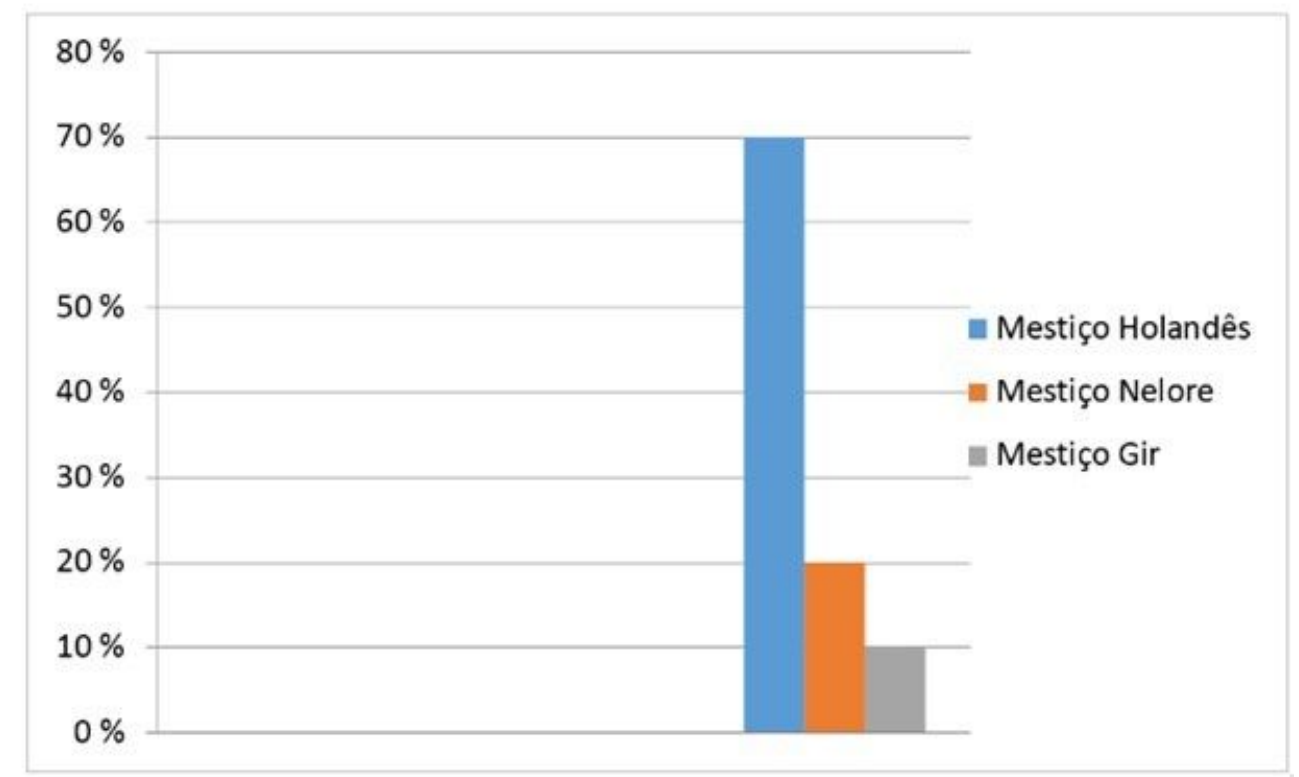

FIGURA 4- Fêmeas bovinas mestiças que primeiramente apresentam cio. 


\section{- Alimentos utilizados para os bovinos}

Em todas as propriedades o sal mineral é utilizado, como forragem são utilizadas a cana-de-açúcar, maniva e a raspa da mandioca, palma forrageira, a silagem do sorgo e o capim Tanzânia, para a formulação do concentrado são utilizados o milho e a soja e a torta de algodão. Nota-se uma carência na oferta de forrageiras, devido ao clima quente, bem como não existiam técnicas de armazenamento nas propriedades estudadas. Para aumentar os rebanhos é necessário melhorar a capacidade de suporte das pastagens que passam a abrigar maior número de animais por hectare (SIGNORETTI, 2014).

\section{- Sanidade}

A principal medida de prevenção que os produtores adotam são as medidas preventivas da saúde animal, sendo que $100 \%$ vacinam o rebanho, regularmente, contra aftosa, $20 \%$ vacinam contra a brucelose, $80 \%$ contra a raiva, $20 \%$ contra manqueira (carbúnculo sintomático) e $20 \%$ vacinam contra botulismo.

As causas mais frequentes de óbitos nos rebanhos bovinos nas dez propriedades são por tristeza parasitária, botulismo, picada de cobra, timpanismo, desnutrição, parto distócico, traumatismos e natimortos. Todas as crias recebem o colostro e $90 \%$ dos produtores realizam a cura do umbigo.

\section{- Manejo da ordenha}

Em 100\% das propriedades o sistema de ordenha é manual, resultado também encontrado por Cavalheiro et al. (2014) na Comunidade São Justino, em Juína (MT).

Sobre as práticas efetuadas durante a ordenha, com a adoção de técnicas de profilaxia, ocorre diminuição significativa na contagem de bactérias do leite, comprovando a importância das práticas de higiene (PEREIRA NETA et al., 2018) e limpeza sobre a qualidade microbiológica do leite (GUERREIRO et al., 2005). Para reduzir a incidência de mamite é recomendado o uso de caneca de fundo preto nos primeiros jatos de leite, no entanto, esta prática é realizada por somente $10 \%$ dos produtores leiteiros da Barreira, valor semelhante aos $11,11 \%$ encontrados por Almeida et al (2015).

Outras práticas higiênicas visando à qualidade do leite, como lavar as tetas antes da ordenha não ocorre $(0 \%)$ em nenhuma propriedade pesquisada, Almeida et al. (2015) em trabalho no agreste pernambucano encontraram que apenas $29,63 \%$ dos produtores utilizam esta técnica.

No entanto, este estudo mostra que $50 \%$ dos produtores lavam as mãos antes da ordenha. A forma de controlar e evitar a ocorrência de mastite em 100\% das propriedades é devido a uma prática comum, a de que todos as crias mamam logo após a ordenha (bezerro ao pé), sendo todo o leite sugado, esvaziando a cisterna e logo após as vacas são soltas no pasto.

Não foi encontrada incidência significativa de mamite, ocorrendo em apenas $20 \%$ dos produtores. Nenhum dos produtores refrigera o leite. A comunidade não possui tanques de resfriamento, individuais ou coletivos. O tempo médio entre a ordenha e a entrega do leite "in natura" é de até quatro horas, em $90 \%$ dos casos, sendo um produtor utiliza o leite para a subsistência de sua família.

\section{- Práticas gerenciais e capacitação tecnológica}

Somente $40 \%$ dos produtores fazem o acompanhamento do custo total de produção de anotar as despesas e receitas antes de participarem dessa pesquisa.

$50 \%$ dos pesquisados anotam os dados de produção do leite por vaca e por 
lactação, isto é o controle leiteiro. Com relação a escrituração zootécnica, isto é, o registro da data de nascimento das crias é prática realizada por $30 \%$ dos produtores. A data da cobertura é anotada por apenas um dos entrevistados que, em todas as propriedades é realizada por monta natural. $50 \%$ dos pesquisados fazem anotações referentes ao manejo sanitário dos animais.

\section{- Instalações dos animais}

Em todas as propriedades havia curral (100\%) de alvenaria coberto com telhas de barro ou de palhas de carnaúba, $20 \%$ possuíam áreas cercadas e sombreadas para as crias, $10 \%$ tinham áreas para novilhas, $40 \%$ possuíam bretes para os manejos de vacinação, 60\% possuíam galpão para ração, mas em nenhuma propriedade tinha pedilúvio. Somente em uma propriedade $(10 \%)$ os animais eram soltos na "manga", retornando ao curral somente as vacas em lactação.

O estudo mostra que há uma série de fatores limitantes ao desenvolvimento da pecuária leiteira no semiárido nordestino brasileiro bem como, existe um baixo nível de capacitação gerencial dos produtores rurais, uma debilidade organizativa com acesso limitado aos serviços de assistência técnica e de extensão rural, aliado a reduzida produtividade pela baixa qualidade genética dos rebanhos.

No entanto, apesar da região Nordeste responder por apenas $11,2 \%$ da produção brasileira de leite, esta configura-se como um importante centro consumidor de laticínios, representando $17,4 \%$ do mercado consumidor no país em 2016, correspondendo a uma demanda da ordem de 1,56 milhões de litros de leite, conforme estimativa calculada com base na pesquisa de orçamentos familiares (IPECE, 2018).

A produção de leite do Ceará está presente nos 184 municípios do estado A quantidade de leite in natura na economia do Ceará é toda produzida no próprio estado, não havendo importação de outros estados brasileiros ou de outro país. O sistema de produção do leite no Ceará é considerado bastante diversificado, onde do total de estabelecimentos que produzem leite no Ceará, $43 \%$ são classificados como de agricultura familiar e 74\% apresentam um rebanho composto por até dezenove cabeças de bovinos, sendo que estes respondem por cerca de $30 \%$ da quantidade produzida de leite in natura.

\section{CONCLUSÕES}

O perfil dos agricultores familiares produtores de leite bovino do município de Barreira (CE) mostra que a atividade está em fase de crescimento, pela abertura destes às inovações de manejo e prevenção. Assim, no futuro próximo haverá uma maior oferta de produtos limpos e saudáveis ao consumidor local.

No município estudado, como em outras regiões do Brasil, a produção leiteira tem importante papel socioeconômico para a segurança alimentar e a manutenção financeira das famílias rurais, o que reduz consideravelmente o êxodo rural.

A bovinocultura de leite apresenta grande potencial, já que a população bovina oferece amplas oportunidades genéticas de adaptação ao clima quente do semiárido, no entanto, ações envolvendo o melhoramento genético do rebanho leiteiro, a melhoria da qualidade e disponibilidade da alimentação animal, além da capacitação e acompanhamento técnico junto ao produtor são determinantes para o processo de evolução da atividade e aumento da rentabilidade do sistema produtivo. 


\section{REFERÊNCIAS}

ALMEIDA, T.J.O.; ARAÚJO, V.V.; FEITOSA, P.J.S.; SILVA, A.F.A. Perfil sociocultural de produtores de leite bovino do município de São Bento do Una (PE) e suas implicações sobre o manejo da ordenha. Revista Brasileira de Higiene e Sanidade Animal, v.9, n.1, p.122-135, 2015. Disponível em: http://www.higieneanimal.ufc.br/seer/index.php/higieneanimal/article/view/229 DOI: http://dx.doi.org/:10.5935/1981-2965.20150013

CAVALHEIRO, C.N.; REMPEL, C.; LAROQUE, F.R.S.; MACHADO, B.N.B. Perfil socioeconômico e análise da qualidade de vida dos produtores de leite da comunidade São Justino, em Juína/MT. Revista Destaques Acadêmicos, v.6, n.3, p.148-156, $2014 . \quad$ Disponível em: http://univates.br/revistas/index.php/destaques/article/download/425/417 Acesso em: $25 / 08 / 2018$

COUTINHO, M.J.F.; CARNEIRO, M.S.C.; EDVAN, R.L.; PINTO, A.P. A pecuária como atividade estabilizadora no semiárido brasileiro. Veterinária e Zootecnia, v.20, n.3, p.9-17, 2013. ISSN 0102-5716 Disponível em: http://fmvz.unesp.br/rvzold/index.php/rvz/article/view/579/464 Acesso em: 28/08/2018

FAO. FOOD AND AGRICULTURE ORGANIZATION OF THE UNITED NATIONS (FAO). Dairy Production and Products - Milk Production. Disponível em: http://www.fao.org/dairy-production-products/en/\#.V3AZwbgrLIV. Acesso em $10 / 08 / 2018$

GALVÃO JÚNIOR, J.G.B.; RANGEL, A.H.N.; GUILHERMINO, M.M.; NOVAES, L.P. MEDEIROS, H.R. Perfil dos sistemas de produção de leite bovino no Seridó Potiguar. Holos, v.2, ano 31, 2015. ISSN 1807 1600. Disponível em: http://arquivos.info.ufrn.br/arquivos/2017021186536a37637282104a05e95cf/19138990-

PB_PERFIL_DOS_SISTEMAS_DE_PRODUO_DE_LEITE_BOVINO_NO_SERID_P OTIGUA.pdf Acesso em 29/08/2018.

GUERREIRO, P.K.; MACHADO, M.R.F.; BRAGA, G.C.; GASPARINO, E; FRANZENER, A.S.M. Qualidade microbiológica de leite em função de técnicas profiláticas no manejo de produção. Ciência e Agrotecnologia, v.29, n.1, 2005. Disponível em: http://www.scielo.br/pdf/cagro/v29n1/a27.pdf Acesso em 25/08/2018.

IBGE. Estatística da produção pecuária. 78p. 2017. Disponível em: ftp://ftp.ibge.gov.br/Producao_Pecuaria/Fasciculo_Indicadores_IBGE/2016/abateleite-couro-ovos_201604caderno.pdf Acesso em 19/08/2018.

IPECE. Instituto de Pesquisa e Estratégia econômica do Ceará. Perfil municipal de Barreira. $18 \mathrm{p}$. 2017.2 Disponível em: http://www.ipece.ce.gov.br/perfil_basico_municipal/2017/Barreira.pdf Acesso em 21/08/2018.

IPECE. Instituto de Pesquisa e Estratégia econômica do Ceará. Análise da Cadeia Produtiva do Leite e seus Derivados no Ceará. N.128, MAIO, 2018. Disponível em: http://www.ipece.ce.gov.br/informe/ipece_informe_128_30_Maio_2018.pdf Acesso em: 20/08/2018.

MANZINI, E. J. Uso da entrevista em dissertações e teses produzidas em um ENCICLOPÉDIA BIOSFERA, Centro Científico Conhecer - Goiânia, v.16 n.28; p.9 
programa de pós-graduação em educação. Revista Percurso, v.4, n.2, p149-171, $2012 . \quad$ Disponível em: http://ojs.uem.br/ojs/index.php/Percurso/article/download/18577/10219 Acesso em: 23/08/2018.

NÓBREGA, G.H.; SILVA, E.M.N.; SOUZA, B.B.; MANGUEIRA, J.M. A produção animal sob a influência do ambiente nas condições do semiárido nordestino. Revista Verde de Agroecologia e Desenvolvimento Sustentável, Mossoró, v.6, n.1, p. 6773 , 2011.Disponível

em: https://www.gvaa.com.br/revista/index.php/RVADS/article/view/592 Acesso em: 22/08/2018.

PEREIRA NETA, I.B.; SILVA, A.R.; SANTOS, G.M.C.; ATHIE, T.S.; REIS, W.C.; SEIXAS, V.N.C. Aplicação das boas práticas agrícolas na produção de leite. Pubvet, v.12, n.5, a94, p.1-8, 2018. Disponível em: http://www.pubvet.com.br/uploads/b18e976a8be2990f710e64078ecdaf29.pdf DOI: https://doi.org/10.22256/pubvet.v12n5a94.1-8

SIGNORETTI, R.D. A importância da melhoria da produtividade e qualidade dos volumosos em sistema de produção de leite. Pesquisa \& Tecnologia, v.11, n.2, 2014. Disponível em: http://www.aptaregional.sp.gov.br/acesse-os-artigos-pesquisae-tecnologia/2014/julho-dezembro/1635-a-importancia-da-melhoria-da-produtividadee-qualidade-dos-volumosos-em-sistema-de-producao-de-leite/file.html Acesso em: $24 / 08 / 2018$

XIMENES, L.J.F. Bovinocultura leiteira no Nordeste: uso racional dos fatores de produção para maiores lucratividade e rentabilidade. Informe Rural ETENE, Fortaleza, ano VIII, n. 2, 2014. Disponível em: https://www.bnb.gov.br/documents/88765/89729/ire_ano8_n2_2014.pdf/262259169d64-49fb-88fd-863b82fe0ab2 Acesso em: 22/08/2018

ZOCCAL, R.; MARTINS, P.C.; CARNEIRO, A.; VASCONCELOS FILHO, R.J.C.R.; NOGUEIRA, J.N.A. Competitividade da cadeia produtiva do leite no Ceará: produção primária. Juiz de Fora: Embrapa Gado de Leite, 2008. 384 p. Disponível em:

http://www.adece.ce.gov.br/phocadownload/Projeto_Leite/1competitividadecadeiapro dutivaleiteceara-producaoprimaria.pdf Acesso em: 22/08/2018. 